\title{
Unraveling the molecular mechanisms that influence the color appearance and stability performance of four lutein crystal forms
}

Wei Guo ${ }^{1}, 2$, Shichao $\mathrm{Du}^{1}$, Shijie $\mathrm{Xu}^{1}$, Yan Wang ${ }^{1}$, Lina Jia ${ }^{1}$, Shiyuan Liu ${ }^{1}$, Songgu

Wu, Junbo Gong ${ }^{1 *}$, Jingkang Wang

1. State Key Laboratory of Chemical Engineering, School of Chemical Engineering and Technology, Tianjin University, Tianjin 300072, PR China

2. Tianjin institute of industrial biotechnology, Chinese of Academy of Sciences.

* Corresponding author

E-mail address: junbo_gong@tju.edu.cn (J. Gong).

\section{Supporting Information}

Table S1 Crystallographic data of the form c and form d lutein solvates

\begin{tabular}{lll}
\hline Crystal form & $\mathrm{c}$ & $\mathrm{d}$ \\
\hline solvent & Methanol & Ethanol \\
Stoichiometry & $1: 2$ & $1: 2$ \\
Formula & $\mathrm{C}_{42} \mathrm{H}_{61} \mathrm{O}_{4}$ & $\mathrm{C}_{44} \mathrm{H}_{68} \mathrm{O} 4$ \\
Crystal system & 629.9 & 660.98 \\
Space group & $\mathrm{P}(1)$ & $\mathrm{P}(1)$ \\
Temperature & 113 & 113 \\
$\mathrm{a}$ & $8.2931(68)$ & $8.4891(17)$ \\
$\mathrm{b}$ & $9.0677(73)$ & $10.273(2)$ \\
$\mathrm{c}$ & $13.6180(110)$ & $13.108(3)$ \\
$\alpha$ & $91.2098(151)$ & $94.10(3)$ \\
$\beta$ & $91.2916(118)$ & $108.09(3)$ \\
$\gamma$ & $94.2400(151)$ & $101.65(3)$ \\
Cell vol & $1020.7(4)$ & $1053.1(4)$ \\
Cell density & 0.9908 & 1.009 \\
\hline
\end{tabular}




\begin{tabular}{|c|c|c|}
\hline$\mu$ & 0.71073 & 0.71073 \\
\hline Radiation type & Mo Ka & Mo K $\alpha$ \\
\hline Crystal form, color & Plate, purple-red & $\begin{array}{l}\text { Wedge, purple- } \\
\text { red }\end{array}$ \\
\hline \multicolumn{3}{|l|}{ Data collection } \\
\hline Diffractometer & Rigaku saturn & Rigaku saturn \\
\hline Data collection method & $\omega$ scans & $\omega$ scans \\
\hline $2 \theta(\max )$ & 25.020 & 25.017 \\
\hline Total reflections measured & 9698 & 10071 \\
\hline Criterion for observed reflections & $\mathrm{I}>2 \sigma(\mathrm{I})$ & $\mathrm{I}>2 \sigma(\mathrm{I})$ \\
\hline Extinction method & SHELXL-2018/3 & none \\
\hline Extinction coefficient & $0.17(6)$ & - \\
\hline Refinement on & $\mathrm{F}^{2}$ & $\mathrm{~F}^{2}$ \\
\hline No. of reflections & 3543 & 6811 \\
\hline No. of parameters & 328 & 449 \\
\hline $\mathrm{R}(\mathrm{F}) \mathrm{I}>2 \sigma(\mathrm{I})$ & 0.1467 & 0.0756 \\
\hline${ }_{\mathrm{w}} \mathrm{R}$ & 0.4121 & 0.1754 \\
\hline Goodness of fit & 1.164 & 1.031 \\
\hline
\end{tabular}
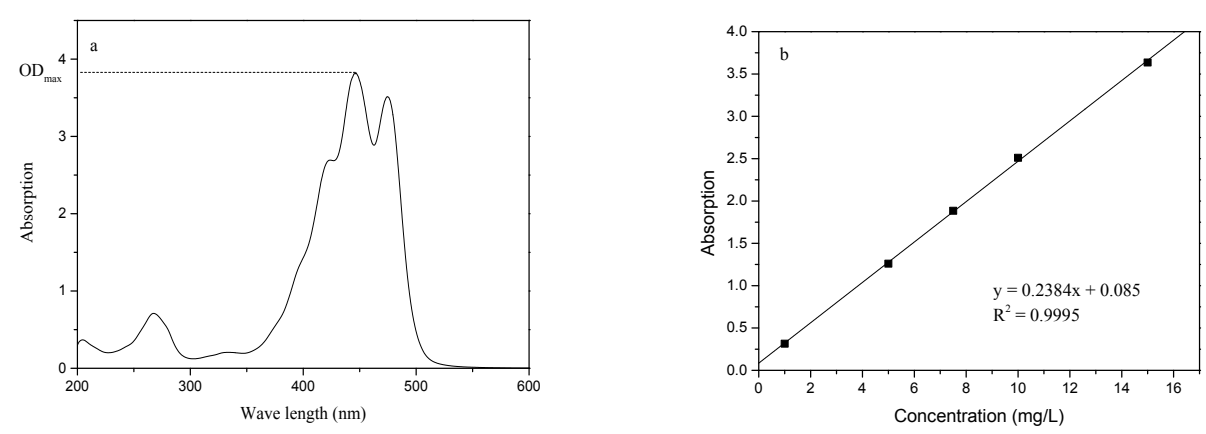

Fig. S1 Typical solution UV/vis spectrum of lutein in ethyl acetate and the calibration curve of lutein solution

a. Typical solution spectrum of lutein in ethyl acetate; b. Calibration curve of lutein solution with range of $1-15 \mathrm{mg} / \mathrm{L}$ 

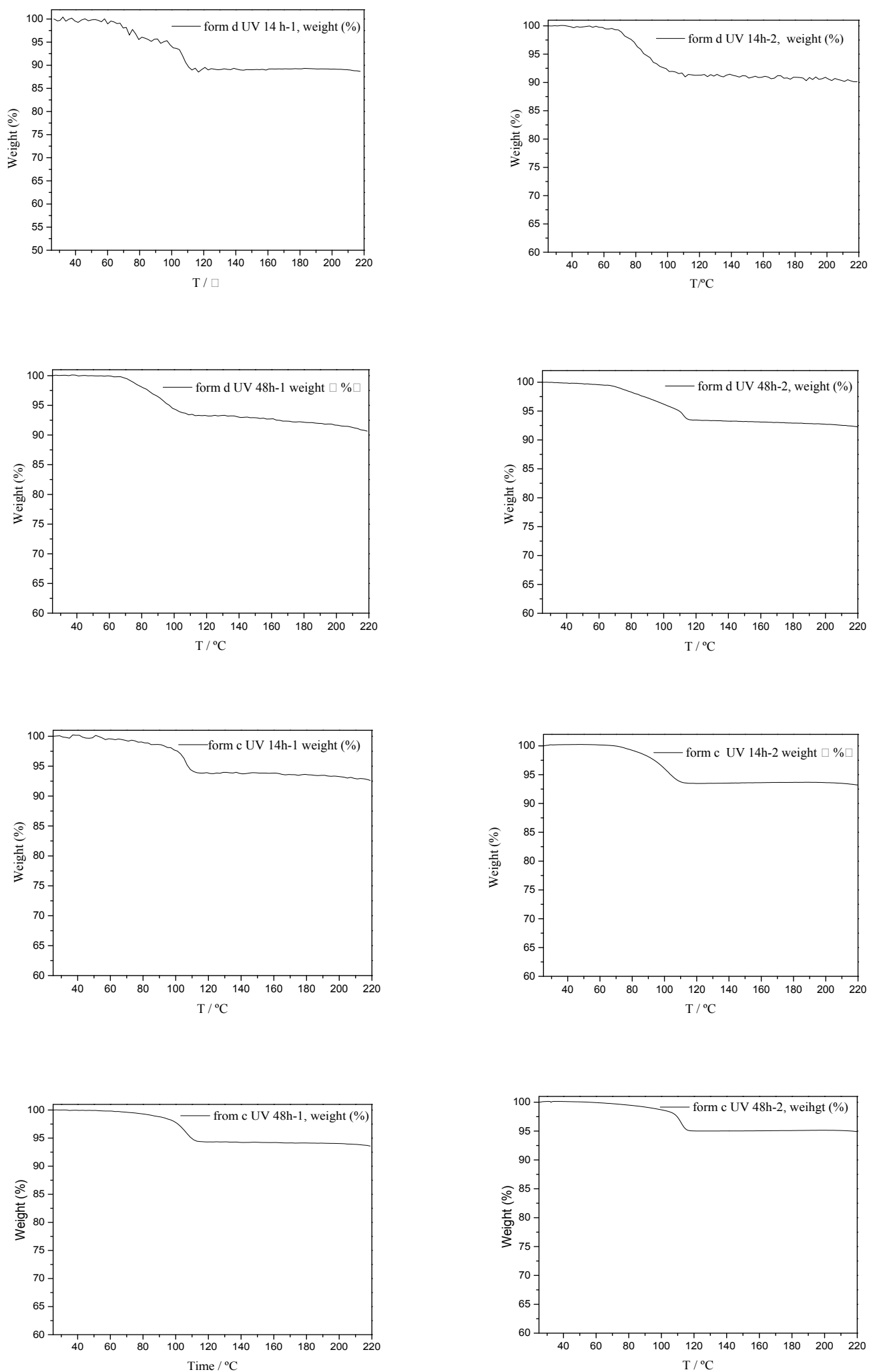

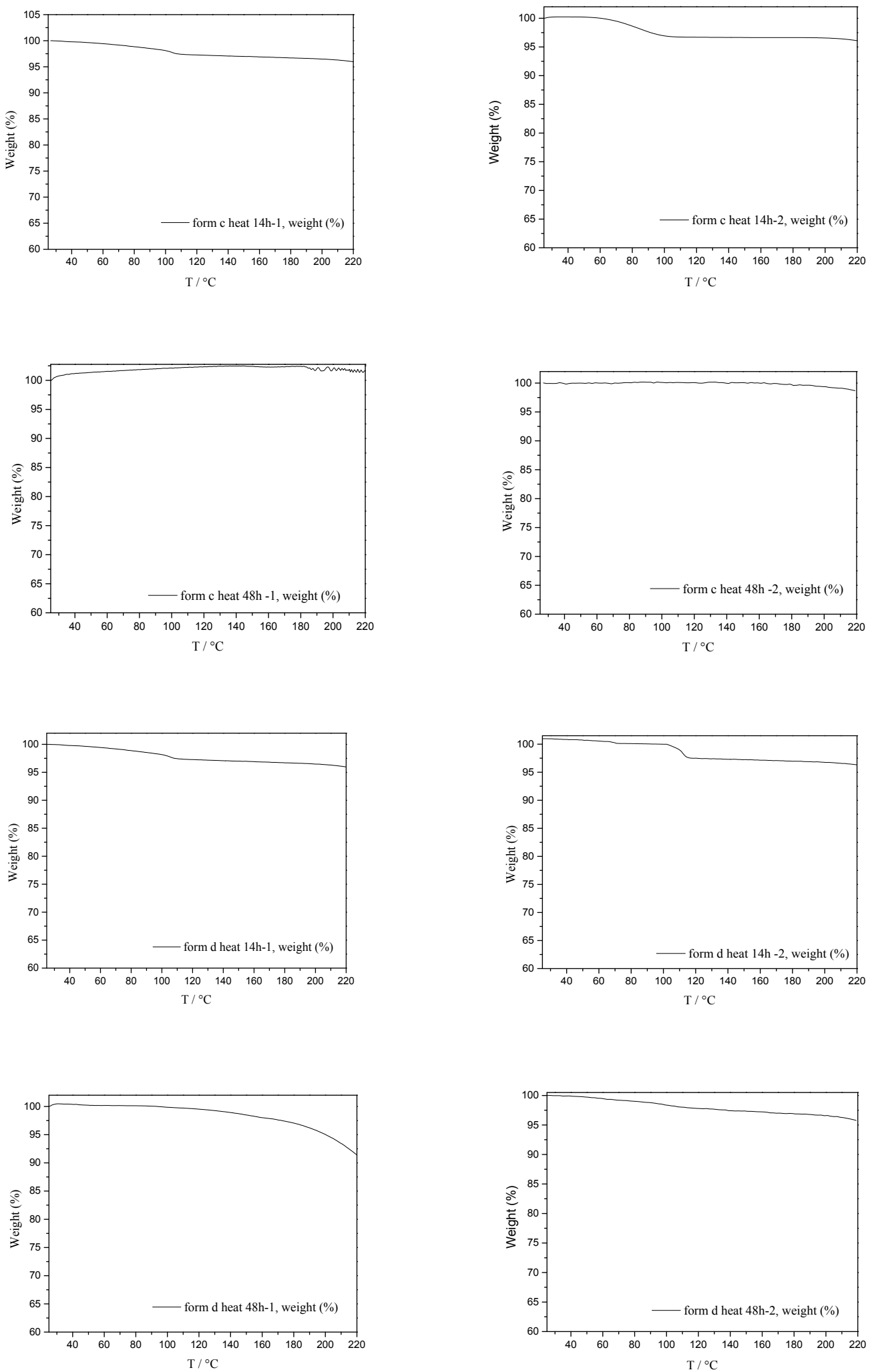

Fig. S2 TGA curve to verify the solvent content of the samples underling stability test.

Parallel samples collected at $14 \mathrm{~h}$ and $48 \mathrm{~h}$ were employed for TGA test to verify the weight change of samples undergoing stability test. 


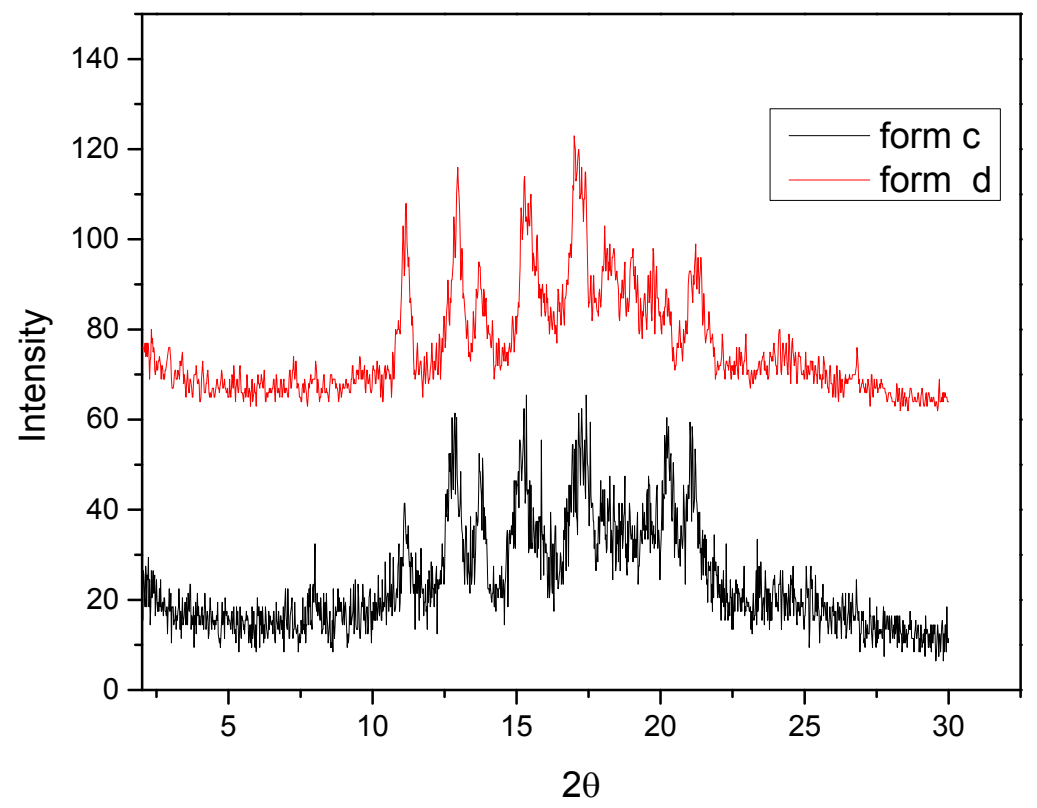

Fig. S3 XRPD pattern of the de-solvation product of form $\mathrm{c}$ and form d lutein crystal.
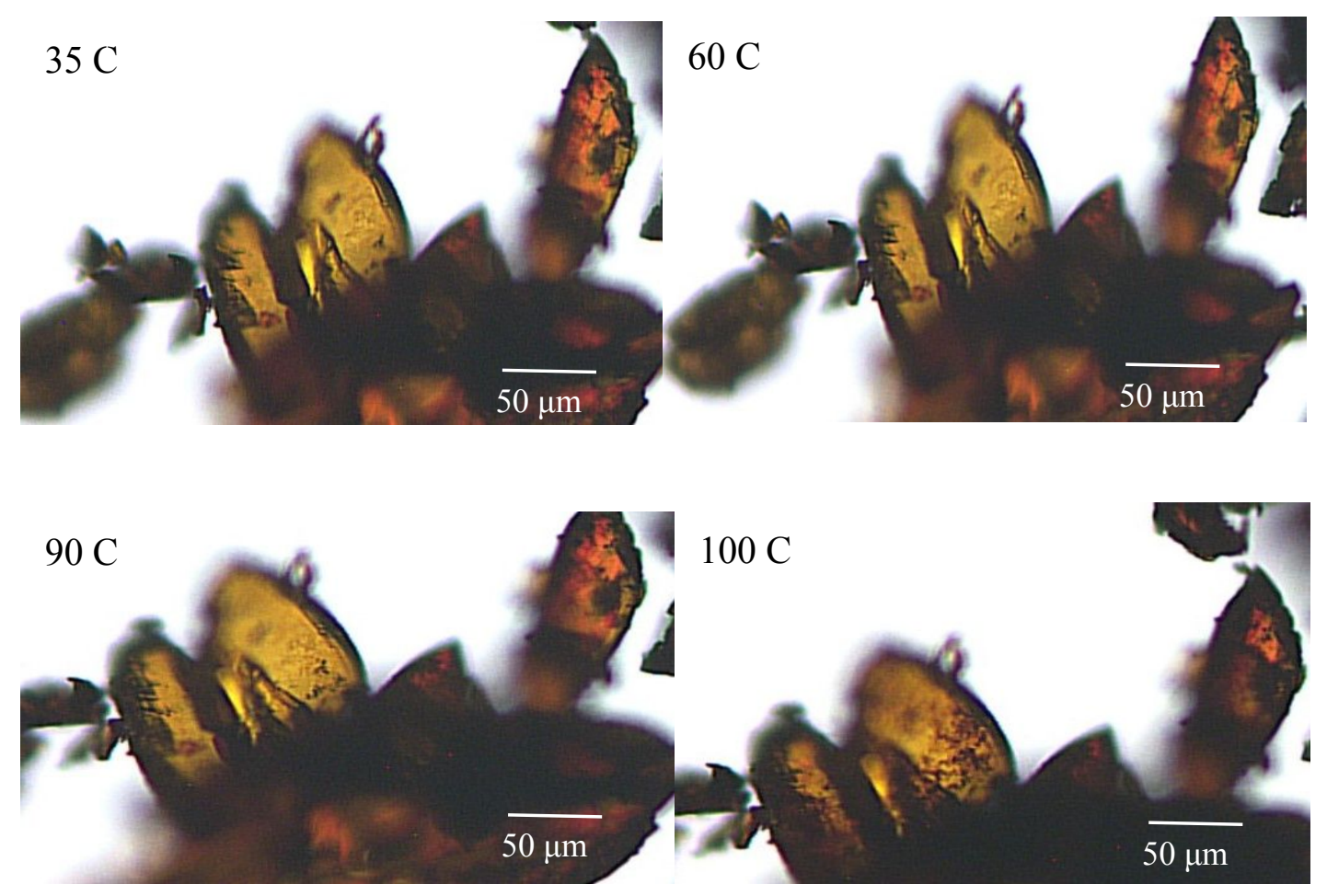

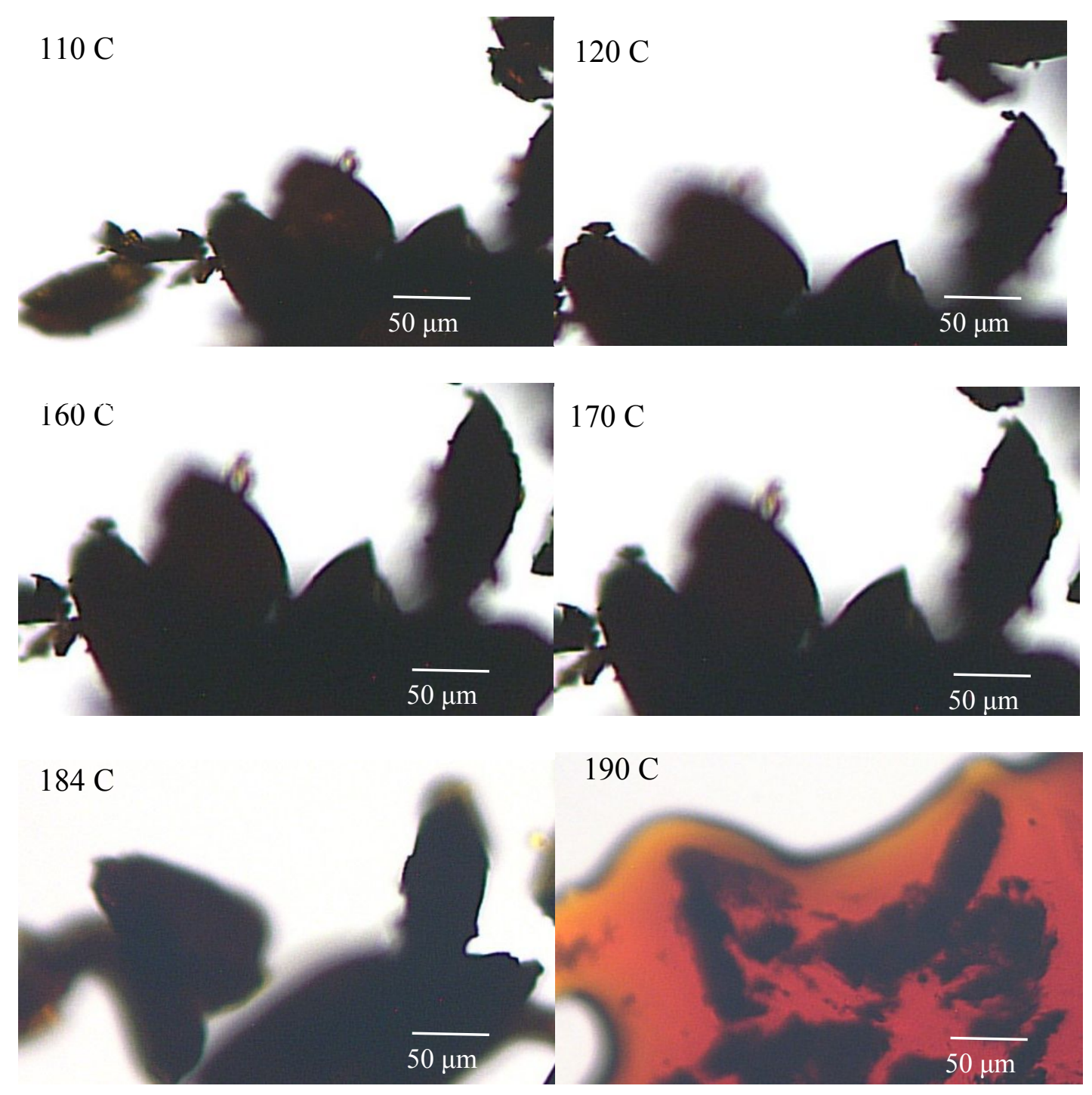

(a)

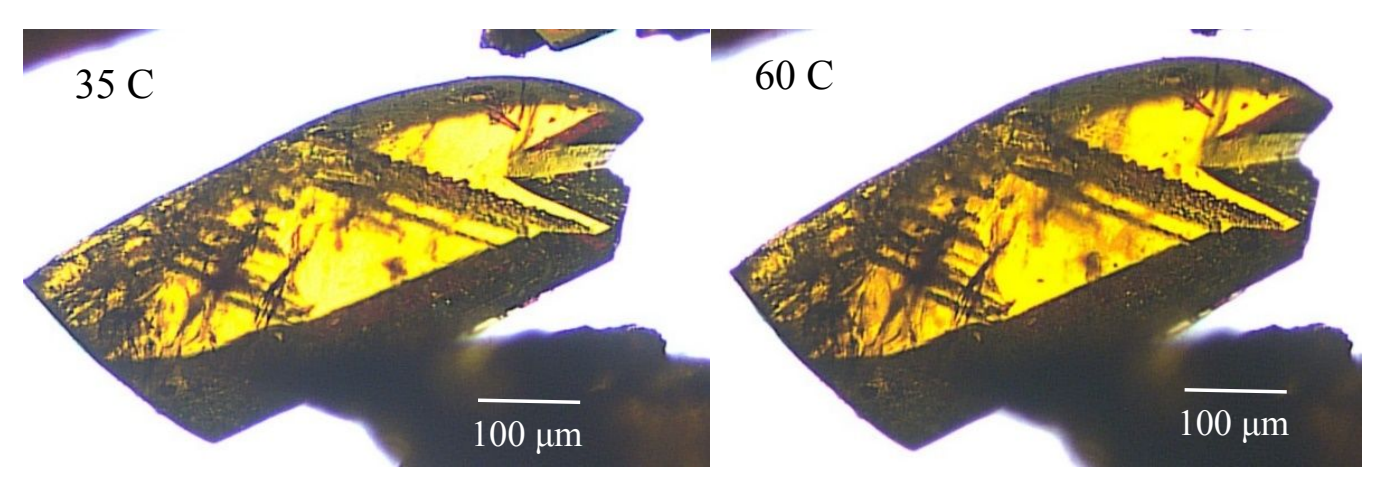




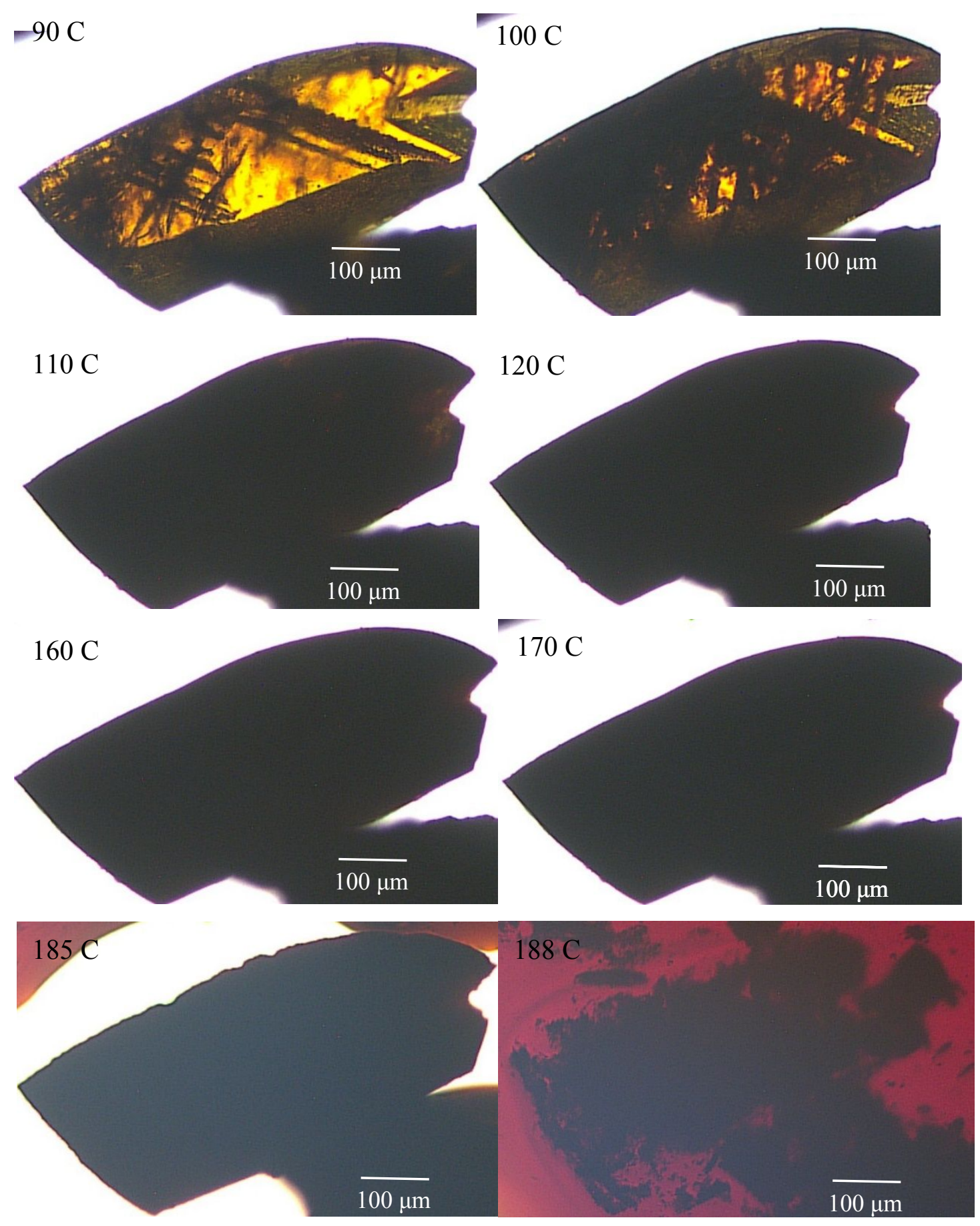

(b)

Fig. S4 The picture captured by HSM of form c (a) and form d (b) at a heating rate of $5 \mathrm{C} \mathrm{min}^{-1}$ 